\title{
Impact of Season and Oral Contraceptive use on Cortisol Levelsin Physically Active Women
}

\author{
L Wikström-Frisén ${ }^{1 *}$, Anna Nordström² ${ }^{2}$ L Mincheva-Nilsson ${ }^{3}$, K Larsén $^{1,4}$ \\ ${ }^{1}$ Department of Community Medicine and Rehabilitation/Sports Medicine Unit, Umeå University, SE-901 87 Umeå, Sweden \\ ${ }^{2}$ Department of Public Health and Clinical Medicine, Occupational and Environmental Medicine, Umeå University, SE-901 87 Umeå, Sweden \\ ${ }^{3}$ Department of Clinical Microbiology/Clinical Immunology, Umeå University, SE-901 85 Umeå, Sweden \\ ${ }^{4}$ The Swedish School of Sport and Health Sciences, Box 5626, SE-114 86 Stockholm, Sweden.
}

Received: May 27, 2016; Accepted: September 21, 2016; Published: September 28, 2016

*Corresponding author: Lisbeth Wikström-Frisén, Department of Community Medicine and Rehabilitation/Sports Medicine Unit, Umeå University, SE-901 87 Umeå, Sweden. Tel: + 4690786 6643; fax: 4690 135692: E-mail address: lisbeth.wikstrom-frisen@umu.se

\begin{abstract}
When athletes optimize their physical performance, an imbalance could occur between the strain of training, time for recovery and the athlete's individual tolerance of stress that could lead to overreaching and overtraining syndrome. Cortisol has been suggested to be a biological, diagnostic marker to detect overreaching and overtraining syndrome, since it is thought to indicate stress. This study aimed to provide normative data on cortisol levels, hence investigate seasonality and impact of oral contraceptive use to elucidate if cortisol could be used as a diagnostic marker to detect overreaching and overtraining syndrome in female athletes. The women, divided in two groups, oral contraceptive users $(n=15)$ and non-users $(\mathrm{n}=18)$, were followed over a nine-month period with monthly blood sampling for cortisol testing and a Profile of Mood State questionnaire (POMS) as a subjective measure of overreaching and overtraining syndrome.Findings indicated seasonal variations in cortisol levels, with different pattern in oral contraceptive users to non-users and moreover, higher cortisol levels in users to nonusers irrespective of season. No differences in seasonal variation in Global POMS score within the groups and no differences in Global POMS score between the groups were detected. Due to seasonality, impact of oral contraceptive use on cortisol levels, methodological considerations and standardization, as well as due to no convincing relationship to Global POMS score, cortisol is not suggested to be an optimal biological, diagnostic marker to detect overreaching and overtraining syndrome in physically active women.
\end{abstract}

Key words: Hormones; Overreaching; Overtraining syndrome; Female Athletes; Profile of Mood State

\section{Introduction}

When athletes optimize their physical performance during seasons there are both physiological and psychological limits, [28]and if imbalance occur between the strain of training, time for recovery and the athletes individual tolerance of stress this could lead to Over Reaching (OR) and Over Training Syndrome (OTS) $[16,22,28,29,31,40]$. OR is defined as an overloading of the body beyond its adaption that needs a relatively short time for recovery $[22,28]$. Whereas OTS is described as the result of an excess of training load with an inadequate recovery between training sessions and periods,[19,30,31] and the time needed for recovery is considered to be much longer compared to OR [22]. Because of both gradual onset of OR and gradual transition from OR to OTS, it is important to detect symptoms at an early stage [30].

No single, specific, and reliable biological parameter to diagnose OR and OTS at an early stage has been found, and there has been only little improvement in recent years in developing tools suitable for diagnostics [1, 22, 30, 45]. Hence, physicians and trainers are looking for new ways to diagnose and monitor athletes that may be at risk $[1,28]$.

The resting cortisol level has been suggested to play an interesting role in detecting OR and OTS since it is thought to indicate stress $[19,31]$. However, levels of resting cortisol has been both increased, decreased and unchanged in over trained athletes, and the research has mainly been performed on male athletes[3,18,25,32,33,44,46].Female athletes have become a common part of the sports environment [21] and since most research has been performed on male athletes, studies on female athletes are warranted. Oral Contraceptive (OC) use is prevalent in female athletes $[21,41]$ and the impact of OC use and non-use on cortisol levels in female athletes are not well studied. Hence the influence of both the exogenous and the endogenous hormonal profiles on athletic performance should be investigated [41]. An administration of estrogen, as in women with OC use, can cause increase in total plasma cortisol [8, 10], and in free cortisol [39]. Coolens et al. [12] showed elevated cortisol levels in estrogen treated women, but unbound cortisol levels were similar to the control group. Since estrogen could influence cortisol levels, studies on female athletes should include both OC users and nonusers. Moreover, since seasonal periodicity in various endocrine functions can occur $[24,37]$ it seems crucial to determine if this may effect cortisol levels differently in OC users and non-users. As the role of cortisol in indicating stress is multifaceted and complex there is a need to investigate both seasonal variation and impact of oral contraceptive use on cortisol levels to evaluate if cortisol could be used to diagnose and monitor female athletes that may be at risk to develop OR and OTS. 
Therefore the aim of the present longitudinal study was to provide normative data on cortisol levels in physically active women, hence investigate seasonality and impact of oral contraceptive use, to elucidate if cortisol could be used as a biological diagnostic marker to detect OR and OTS.

\section{Materials \& Methods}

\section{Subjects}

Forty-eight healthy and physically active women between 1835 yr., 29 with OC use and 19 without OC use, recruited at a local gym, volunteered to take part in the study. They were physically active at least 3 times a week at a level not less than 13 on the Borg RPE scale $[6,7]$ corresponding to 7 on the scale for training intensity in POMS questionnaire, and informed to continue to be physically active during the study and assert at least two days of rest every week. All subjects gave written informed consent to participate in the study, and all procedures were approved by The Regional Ethical Review Board (Dnr 05-148M). The subjects were non-smokers, medically screened to ensure that they did not have any medical problems that would compromise their participation. Subjects with an irregular menstrual cycle history were excluded from the study. Thirty-three subjects, women with OC use, $n=15$ and women without OC use, $n=18$ completed the study. The reasons for discontinuation were: changing from oCuse to non-use and vice versa $(n=5)$, absence from more than two consecutive tests $(n=5)$, other reasons $(n=4)$ and pregnancy $(n=1)$. No significant differences were seen between the study group and discontinuers with and without OC use respectively at baseline in subject characteristics except that the discontinuers with OC use $(n=4)$ were heavier $(p=0.012)$ than the subjects with OC use $(n=15)$. Among the women who completed the study, 13 used combined estrogen-gestagen type of OC, one used combined anti-androgen and one used OC with only gestagen. At inclusion the 18 women without OC use had menstrual cycles of 21-35 days. OC users and non-users, were comparable in terms of subject characteristics at baseline for height and weight but not for age $(\mathrm{p}=0.006)$ and $\mathrm{VO}_{2} \max (\mathrm{ml} / \mathrm{kg} \times \mathrm{min})(\mathrm{p}=0.037)$. Subjects without OC use were older and had lower $\mathrm{VO}_{2} \max (\mathrm{ml} / \mathrm{kg} \mathrm{x} \mathrm{min})$ at baseline. The same significant differences remained at the end of the study which indicates that aerobic training was constant during the study in both groups. The study was performed in a setting with different daylight hours during the seasons. The amount of hours from sunrise to sunset at the location in this study was in average of $10 \mathrm{~h}(6.5 \mathrm{~h}-13 \mathrm{~h})$ during the autumn, $6 \mathrm{~h}$ (4.5h-8.5h) during the winter, and $15 \mathrm{~h}$ (11h-18h) during the spring ( U.S. Naval Observatory Astronomical Applications Department).

\section{Study design}

At inclusion, height, weight and aerobic performance were measured, blood samples were collected and the regular length of the menstrual cycle and day of menstrual/OC cycle were documented. Finally, the Swedish POMS questionnaire (licensed Data Medic AB \& Malabo AB, copyright EdITS) [35] including a rating scale for estimated training intensity during the last week was filled out. Once a month during the study, POMS questionnaire was filled out, blood samples were collected, weight was measured and day of menstrual/OC cycle was documented to ensure that different days of the menstrual cycle were represented as in an ordinary training situation for women. At the end of the study, to evaluate the training load during the study, aerobic performance and weight were measured, blood samples were collected and POMS questionnaire were filled out. A personal daily logbook was given to each subject for recording exercise, to ensure training load within the given prescription and furthermore note if any health problem occurred during the study period. Aerobic performance was assessed with an incremental test on an electronically braked bicycle (Monark, 839 E, Sweden) with a metabolic gas measurement system (Meta Max II, CORTEX, Bio physic GmbH, Leipzig, Germany), method described in Gilenstam et al. [20]. For each individual, the cycle ergo meter tests were identically performed at the two occasions, approximately at the same time of the day and with same technical assistance.

\section{Blood sample collection}

Blood samples for detection of total serum cortisol and Corticosteroid-Binding Globulin (CBG)were collected once a month, from September to May, giving a total of 9 samples for each subject allocated into three seasons, the autumn (September, October, November), the winter (December, January, February) and the spring seasons(March, April, May). A solitary missing value for one month was completed with calculated mean of the existing values from that season and when values for two months were missing the existing value was used as mean for that season. The blood samples were collected for each subject, with maximal one-week difference between calendar days at different days of the menstrual cycle to represent the whole menstrual cycle. The samples were drawn in a seated position at $0730 \mathrm{~h}-0830 \mathrm{~h}$, about 45-60 minutes after a light breakfast without any heavy physical activity or stress before the sampling to resemble an ordinary life situation. Samples of cortisol were collected into plastic tubes and standard laboratory analyses were performed. Samples of CBG were collected into chilled EDTA-containing plastic tubes, put on ice directly and immediately centrifuged at 1,600 $\mathrm{x}$ g for 15 minutes at $0^{\circ} \mathrm{C}$. The plasma was then stored at $-80^{\circ} \mathrm{C}$ until laboratory analyses. Analyse of CBG level was not a standard analyse at the clinical chemical laboratory of the university hospital hence samples were stored until all analysis could be performed at the same time to assert standardized assay with same analyse kit and same calibration.

\section{Measurement of serum-cortisol}

Total serum-cortisol levels wereanalyzed inthe university hospital, an accredited clinical chemical laboratory, by Roche Elecsys reagents on Modular E170analysers. The reference range for serum-cortisol given by the laboratory when blood was taken in the morning at $0700 \mathrm{~h}$ was200-800 $\mathrm{nmol} / \mathrm{L} \mathrm{[38].}$

\section{Measurement of CBG}

The CBG levels were analysed by ELISA methodology using a commercial ELISA kit from USCN Life Science Inc and following the manufacturer's instructions. First, a pilot experiment was 
performed to determine the optimal dilution for the plasma samples. The samples were diluted to their optimal dilution $(200$ fold) in $0.02 \mathrm{mmol} / \mathrm{L}$ PBS as recommended. Seven standards were prepared by dilution from a stock standard. One hundred $\mathrm{L}$ of the different standard concentrations, samples and blank were plated in pre-coated 96-well microtiter plates and the ELISA protocol was performed as described by the manufacturer. The optical density of the colour reaction (OD) was immediately measured in a micro plate reader at $450 \mathrm{~nm}$ wave length. The CBG concentrations (ng or $\mathrm{g} / \mathrm{mL}$ ) in the individual samples were calculated from a standard curve, prepared with OD values from 7 CBG concentrations prepared by 2 -fold dilutions of the stock standard and ranging from $100 \mathrm{ng} / \mathrm{mL}$ to $1,56 \mathrm{ng} / \mathrm{mL}$.

\section{Estimation of free cortisol}

A modified model, cortisol/CBG ratio, was used to estimate the free cortisol [5].

\section{The Profile of Mood State}

The Profile of Mood State (POMS) was used in this study due to its feasibility in sport and exercise studies to evaluate OR and OTS $[1,35]$. The POMS test is a 65 -item self-report questionnaire which provide an index of total mood disturbance (Global POMS score), measured by six mood states (tension, depression, anger, fatigue, confusion and vigour)on a five-point scale from not at all (0) to extremely (4)[35], adding a constant of 100 to prevent the occurrence of negative score in Global POMS $[4,13,40]$. The standard instruction of the POMS questionnaire was used, i.e. the subjects answered the question, "How have you been feeling during the past week including today?" [35]. To estimate training intensity a rating scale from 2 (very, very low) to 14 (very, very high)was used to see if high Global POMS score and decreased Vigor/Fatigue ratio (V/F ratio)were connected to high training intensity and therefore could be a sign of developed OR and OTS due to training load.

\section{Statistical analysis}

Data were analysed with the Statistical Package for the Social Sciences (SPSS v19). Level of statistical significance was set at $\mathrm{p}<0.05$. Conventional methods were used to calculate the means and Standard Deviations (SD). Paired Samples T-Test was used when comparing means within groups and Independent Samples Test was used when comparing means between groups. Statistical analyses of serum-cortisol levels, CBG levels and Global POMS scores showed normal distribution in the two study groups, and no extreme outliers were identified that interfered substantially with the analysis.To evaluate seasonal variations in serumcortisol, CBG, cortisol/CBG ratio and Global POMS, repeated measures analysis of variance was used, with season as a withinsubject variable and group as between-subject variable. When the sphericity assumption was violated based on Mauchly's test, the Huynh-Feldt adjustment was used. If there was a significant interaction between season and group, the data were split by the group variable and the seasonal variable, respectively. When data was split by group, repeated measures analysis of variance with season as a within-subject variable and no between-subject variable was used. If it was found significant, contrast analysis were used to establish which season that differed. When data was split by season Independent Samples Test was used to compare groups for each season.

To clarify the relationship between day in the menstrual/ OC cycle and serum-cortisol levels, the linear regression was used and $\mathrm{R}^{2}$ was calculated and significant correlations were reported. Due to related observations, with each individual represented multiple times during the study, the p-value could not be calculated for the whole study group. Instead analyzes were performed for each individual separately and the number of significant correlations in women with and without OC use respectively, were summarized.

\section{Results}

The two study groups, women with OC use and without OC use, were comparable in terms of subject characteristics for height $(1.66 \pm 0.06 \mathrm{~m}$ vs. $1.68 \pm 0.07 \mathrm{~m})$ and weight $(61 \pm 6 \mathrm{~kg}$ vs. $67 \pm 13 \mathrm{~kg}$ ). Women with OC use were a few years younger ( $23 \pm 3$ yrs. vs. $26 \pm 4$ yrs; $p=0.006$ ) and had a slightly higher $\mathrm{VO}_{2} \mathrm{max}(\mathrm{ml} / \mathrm{kg} \mathrm{x} \mathrm{min})$, both at inclusion $(50.0 \pm 4.7 \mathrm{ml} / \mathrm{kg} \mathrm{x} \mathrm{min}$ vs. $46.4 \pm 4.6 \mathrm{ml} / \mathrm{kg} \mathrm{x} \mathrm{min;} \mathrm{p}=0.037$ ) and at the end of the study ( $49.9 \pm 5.0 \mathrm{ml} / \mathrm{kg} \mathrm{x}$ minvs. $45.3 \pm 6.1 \mathrm{ml} / \mathrm{kg}$ x min; $\mathrm{p}=0.040)$. Mean estimated training intensity on the Borg RPE scale was equal in women with and without $O C$ use $(15 \pm 2$, vs. $15 \pm 2)$ during the study period.

Mean value and SD of serum-cortisol levels (nmol/L), cortisol-to-CBG ratios and mean seasonal daylight hours from sunrise to sunset during the winter, the autumn, and the spring seasons for women without OC use (samples; $n=127$, missing samples $n=8$ )and with OC use (samples; $n=162$, no missing samples) respectively are presented in Table 1 .Women with OC use peaked in the spring season $(1074 \mathrm{nmol} / \mathrm{L} \pm 135)$ and the lowest mean value was detected during the autumn $(926 \mathrm{nmol} / \mathrm{L}$ \pm 210 ). Women without OC use peaked in the winter season (585 $\mathrm{nmol} / \mathrm{L} \pm 99$ and the lowest mean value was detected during the spring season (554 nmol/L \pm 102 ) (Table 1). No clear tendency

Table 1: Mean levels and SD of serum cortisol (nmol/L),cortisol-to-CBG ratiosand mean hours of daylight hours in women with and without oral contraceptive use.

\begin{tabular}{|l|l|l|l|}
\hline $\begin{array}{l}\text { Women withoutoral } \\
\text { contraceptives, } \\
\text { n=18 }\end{array}$ & $\mathbf{6}$ (Winter) & $\mathbf{1 0}$ (Autumn) & $\mathbf{1 5}$ (Spring) \\
\hline $\begin{array}{l}\text { Serum-cortisol level } \\
585 \pm 99\end{array}$ & $570 \pm 93$ & $554 \pm 102$ \\
\hline $\begin{array}{l}\text { Cortisol-to-CBG } \\
\text { ratio }\end{array}$ & $120 \pm 33$ & $119 \pm 34$ & $121 \pm 38$ \\
\hline $\begin{array}{l}\text { Women with oral } \\
\text { contraceptives, } \\
\text { n=15 }\end{array}$ & $268 \pm 108$ & $257 \pm 125$ & $286 \pm 86$ \\
\hline $\begin{array}{l}\text { Serum-cortisol level } \\
\text { Cortisol-to-CBG } \\
\text { ratio }\end{array}$ & $1022 \pm 254$ & $926 \pm 210$ & $1074 \pm 135$ \\
\hline
\end{tabular}

Note: Corticosteroid-binding globulin (CBG) 
for cortisol levels (serum cortisol and cortisol-to-CBG ratio)to neither increase nor decrease with changes in hours of daylight in the autumn, the winter and the spring seasons, was observed (Table 1). Further, when analyzing seasonal variation in serumcortisol levels in the whole study group a significant interaction between season and group was found $(p=0.001)$. Separate analysis of women with OC use and without OC use showed significant seasonal variations in serum-cortisol level in women with OC use $(\mathrm{p}=0.008)$.Further statistical analyzes displayed significant differences between the autumn and the winter seasons $(p=0.001)$ and between the autumn and the spring seasons( $p=0.005)($ Fig. 1).Comparing serum-cortisol levels between women with and without OC use in each season showed significantly higher mean levels of serum-cortisol in women with OC use both in the autumn ( $p<0.001)$, the winter $(\mathrm{p}<0.001)$ and the spring seasons $(\mathrm{p}<0.001)$. In women without OC use no significant seasonal variation in serum-cortisol was observed (Fig. 1). When analyzing CBG levels $(\mu \mathrm{g} / \mathrm{mL})$ in the whole study group no significant interaction between season and group was found, and CBG levels in women without OC use showed significantly higher mean level of CBG in the spring season than women with OC $(p=0.048)$ (Fig. 2).Neither was any significant interaction between season and group found when analyzing seasonal variations in cortisol-to-CBG ratio in the whole study group. Though the cortisol-to-CBG ratios was significantly higher in women with OC use in the autumn $(\mathrm{p}=0.001)$, the winter ( $\mathrm{p}$ $<0.001)$ and the spring seasons $(\mathrm{p}<0.001)$ compared to women without OC use (Fig. 3). Women with and without OC use showed no significant seasonal variation in Global POMS score within the groups respectively and no significant differences in levels of Global POMS score between the groups were found (Fig.4).The relationship between day in the menstrual/OC cycle and serum cortisol level showed three significant correlations, two women with $\mathrm{OC}$ use $(\mathrm{p}=0.029$ and $\mathrm{p}=0.005)$ and one woman without $\mathrm{OC}$ use $(\mathrm{p}=0.014)$

\section{Discussion}

The results in this study indicated that cortisol is not an optimal biological diagnostic marker to detect OR and OTS in

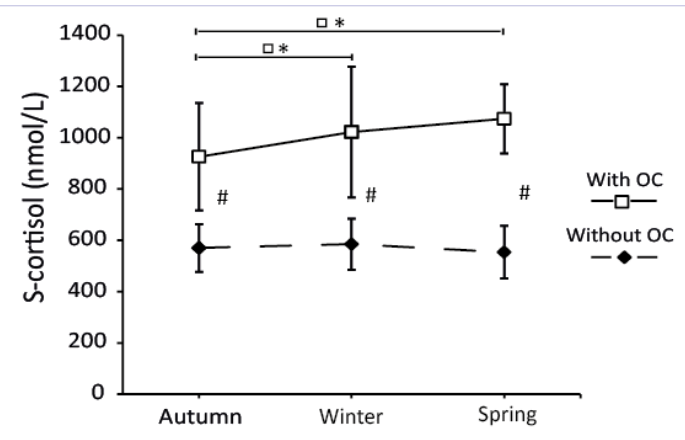

Figure 1: Average concentration of serum-cortisol (S-cortisol)levels in women with and without oral contraceptives (OC) in the autumn, the winter and the spring season (mean $\pm 1 \mathrm{SD}$ ). Statistically significant seasonal variations are shown in women with OC $\left({ }^{*} p<0.05\right)$.Statistically significant differences in S-cortisol levels between the groups are shown $(\# \mathrm{p}<0.05)$.

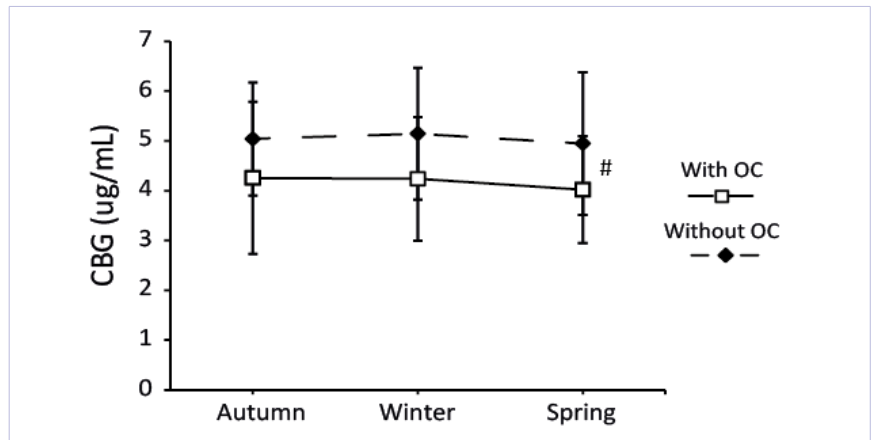

Figure 2: Average concentration of Corticosteroid-Binding-Globulin (CBG) levels $(\mu \mathrm{g} / \mathrm{mL})$ in women with and without oral contraceptives (OC) in the autumn, the winter and the spring season (mean $\pm 1 \mathrm{SD}$ ). No statistically significant seasonal variations are found in CBG within women with and without oral contraceptives respectively.Statistically significant differences in levels between the groups are shown (\# $\mathrm{p}<0.05$ ).

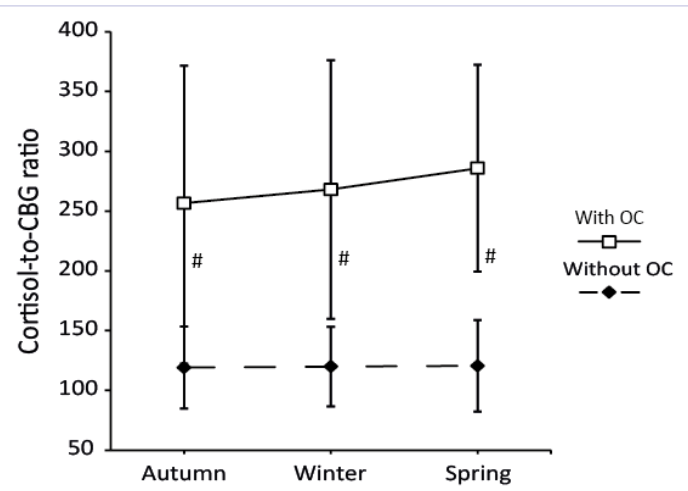

Figure 3: Average concentration of cortisol-to-corticosteroid-binding globulin ratio (cortisol-to CBG ratio) in women with and without oral contraceptives $(\mathrm{OC})$ in the autumn, the winter and the spring season (mean $\pm 1 \mathrm{SD}$ ). No statistically significant seasonal variations are shown in women with and without OC respectively. Statistically significant differences in levels between the groups are shown (\# p<0.001).

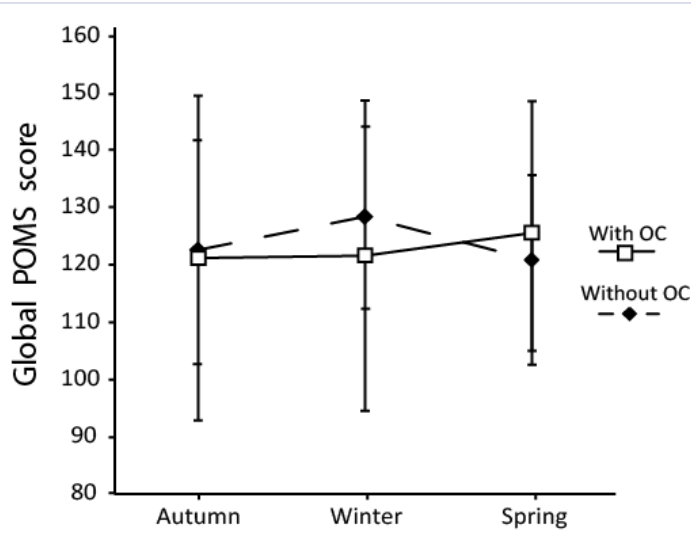

Figure 4: Average Global Profile of Mood State (POMS) scores in women with and without oral contraceptives (OC) in the autumn, the winter and the spring season (mean $\pm 1 \mathrm{SD}$ ). No statistically significant seasonal variationsare shown in Global POMS scoreswithin women with oral contraceptives( $\square$ ) and without oral contraceptives $(\downarrow)$ and no statistically significant differences in levels between the groups are shown. 
physically active women, due to both its seasonality and impact of OC use. We found seasonal variations in cortisol levels with a different pattern in OC users to non-users and more over higher cortisol levels in OC users to non-users irrespective of season. Hence, confident normative data on cortisol in physically active women could not be provided. This implies, when designing studies, analyzing and interpreting results of cortisol measurements, time of year for measurements and the use of OC are issues that must be considered.

In sport it is of importance to optimize performance, hence balance between training stress and recovery is a critical situation. That is why monitoring instruments, POMS and blood samples, besides training, recovery, and performance data, are important to assess the risk of OR and OTS[19,27,28,30,40].

The seasonal periodicity, [47] and circadian rhythms $[12,24,37]$ in endocrine functions, including cortisol, have earlier been investigated, though a possible effect of marked daylight hours on seasonal periodicity has not been clarified. Hence, we studied the seasonality of cortisol and at the same time we examined if cortisol interacted with marked variability in daylight hours over a nine-month period in women living at high latitude. Data showed seasonality in cortisol levels in OC users, though probably not influenced by the number of daylight hours at this location. Even though this kind of geographic location is suitable for studies of seasonal variations in hormones, neither the season with the longest nor the shortest average daylight hours showed a clear relation to high or low mean cortisol levels in women with or without OC use, respectively. These findings demonstrated that the seasonality in cortisol must be taken in consideration, as earlier suggested [47], though our findings also indicated that it was irrespective of variability of daylight hours at high latitude. Hence, seasonal and circadian variation must be taken in consideration when studying cortisol levels. By inference, there are difficulties to standardize cortisol measurements in comparative studies.

Previous studies on cortisol have mostly been performed on male athletes and if female athletes participated, they were few and the impact of OC use vs non-use was not completely investigated. Since female athletes, OC users and non-users, have become a common part of the sports environment [21, 41], they could be at the same risk to develop OR and OTS, as male athletes $[16,22,28,29,31,40]$. As cortisol has been suggested to play a role in detecting OR and OTS $[19,31]$ we found it necessary to study the effects on cortisol levels of exogenous and endogenous hormonal profiles in physically active women. Our results of markedly increased cortisol levels in OC users have also been demonstrated in other non-sporting female cohorts when women received estrogen or were pregnant $[2,8,10,14,47,48][8,10,47]$ or used OC $[2,14,48]$. Cortisol was increased in the previous studies due to both triphasic OC [2] and mono phasic OC [14] use, though the women in these studies were not physically active. Moreover, our results showed higher cortisol levels, both total and free cortisol, in OC users compared to non-users and irrespective of season. These findings make it important to consider OC use in studies of cortisol, regardless of cortisol is measured as total or free cortisol.
It is known that in OR and OTS, athletes report negatively elevated mood scores and greater perceptual changes in comparison to healthy athletes [29].To date, impairment of physical performance and disturbed mood profile, i.e. an increased Global POMS and a decreased V/F ratio, [4, 29, 31, $40]$ seems to be the most reliable diagnostic markers of OR and OTS [1]as symptoms often described are fatigue, depression, disturbances in self-perception and mood $[4,29,31,40]$. Results in the present study of mean Global POMS scores during the study period varied between 120 to 130 in both OC users and non-users and these scores were not considered as negative elevated [13]. Hence The Global POMS scores, and the rated perceived exertion of the training load, did not indicate an imbalance in body homeostasis in the subjects during this study. Since seasonal periodicities could influence the relation of cortisol to Global POMS score, it is of importance to control if used as a diagnostic tool to detect signs for OR and OTS. However, there were no seasonal variations in Global POMS score within the groups and no differences in Global POMS score between the groups. Since the seasonal Global POMS scores neither resembled the seasonal pattern of cortisol, nor corresponded to the increased levels of cortisol in OC users, and further no high rated training load was observed, we could not suggest that the high cortisol levels were related to OR and OTS in this study.

\section{Limitations and methodological aspects}

The drop-out rate in the present study could most likely be explained by the long study period and the young study population and their change of living conditions and contraceptive habits which resulted in difficulties with high attendance.However, the discontinuers did not differ substantially from the study group in subject characteristics. The remaining subjects, divided in OC users and non-users, were regarded as comparable in subject characteristics andin mean training load during the study period.

When research is performed in OC users it is important to consider type of OC, since CBG and cortisol are affected by the hormones in OC $[48,49]$.In the present study the majority of OC users, (13 out of 15 women) used combined estrogen-gestagen, one used combined anti-androgen and one used OC with only gestagen, hence assumed not to have influenced the results.

Analysis of the individual relations between day in menstrual/ OC cycle and cortisol levels during the study only showed three significant relations, which indicated that cycle day probably not had an impact and could not explain the differences in cortisol levels between OC users and non-users.

To determine cortisol levels both methodological and standardization requests must be considered to ensure an assertive sampling procedure [38]. Hence, we ensured that the blood samples were collected with the same routine during the study. Further, in CBG analysis arapid treatment of blood samples were performed to intend a minimized decomposition process after the sample collection. Hence, these analyses are considered to be confident. Though a variability of the laboratory methods leads to difficulties when comparing the values in other studies. Cortisol is commonly reported both as total cortisol and 
free cortisol. It is known that cortisol exists in plasma in three forms, $80-90 \%$ bound with high affinity to CBG, about 10-14\% associated with albumin and about $6-10 \%$ in unbound form as free cortisol $[8,9,10,12,23,26,34,39,42]$ and it is suggested that only the free cortisol is biological active $[8,10,12,36,42]$.There are several techniques for measurements and calculations of free cortisol but many of them are not suitable for routine laboratory use $[5,11,12,15,17,43]$. In this study we used a modified model (cortisol/CBG ratio) of the Free Cortisol Index [5].In our study we found no seasonal variations in the calculated cortisol-toCBG ratio neither in OC users nor in non-users. These data were in contrast to our results of seasonal variation in total cortisol levels. Hence, results in this study revealed that total cortisol and the cortisol-to-CBG ratio were not completely confident measurements to provide normative cortisol levels in female athletes. CBG is increased by estrogens and most of the increase in total cortisol is due to a rise in the CBG-bound fraction [10]. Though the high levels of cortisol found in this study could not be explained by concomitantly higher CBG levels in women with OC, but seem to be a true difference in cortisol. Compared to the traditional view that no such difference exist in cortisol levels, this could be due to lower levels of estradiol in modern OC.

Future research in hormone measurements is warranted in physically active women to investigate essential links to interpret adaption's to physical exercise and recovery and to detect sufficient diagnostic biological markers for OR and OTS. Moreover the studies in physically active women should include non-users and OC users and be specific in types of OC.

\section{Conclusions}

Due to impact of season and oral contraceptive use on cortisol levels, and moreover due to many methodological and standardization requests at the sampling procedure, cortisol is not suggested as an optimal biological diagnostic marker to detect OR and OTS in physically active women. Further, no corresponding and convincing pattern between cortisol levels and Global POMS scores were detected, which implied that an increased cortisol level in the OC users probably not could be considered as signs of training stress as in overtraining. Hence, physicians and trainers, who diagnose and monitor athletes that may be at risk, should be aware of that cortisol is an unreliable diagnostic marker in female athletes; though to date it is still used. Therefore future research is warranted to develop other reliable diagnostic markers, due to that the differences in cortisol levels in oral contraceptive user vs non-user makes it inapplicable.

\section{Acknowledgements}

We want to thank Lotta Alfredson, Lennart Burlin, Inger Holmlund, Erkki Jakobsson, Anita Ljungberg, and Torsten Sandström at the Department of Surgical and Perioperative Sciences, Sports Medicine Unit for skillful technical assistance during the study period, Leif Nilsson, Mathematics and Mathematical Statistics, for his assistance in statistical analysis. The skillful technical assistance of Olga Nagaeva, Department of Clinical Microbiology/Clinical Immunology in the analysis of CBG is gratefully acknowledged. We would also like to thank The Alfredson Foundation and foundations administered by
Umeå University and distributed by the Faculty of Medicine for financial assistance.

Conflict of interest: The authors declare that there is no conflict of interests.

\section{References}

1. Ackel-D’Elia C, Vancini RL, Castelo A, Nouailhetas VLA, Silva AD. Absence of the predisposing factors and signs and symptoms usually associated with overreaching and overtraining in physical fitness centers. Clinics. 2010;65(11): 1161-1166. doi: 10.1590/S180759322010001100019 .

2. Aden U, Jung-Hoffmann C, Kuhl H. A randomized cross-over study on various hormonal parameters of two triphasic oral contraceptives. Contraception. 1998;58(2): 75-81.

3. Adlercreutz H, Harkonen M, Kuoppasalmi K, Naveri H, Huhtaniemi I, Tikkanen $\mathrm{H}$, ea tl. Effect of training on plasma anabolic and catabolic steroid hormones and their response during physical exercise. Int J Sports Med. 1986;7 Suppl 1: 27-28.

4. Berglund B, Safstrom H. Psychological monitoring and modulation of training load of world-class canoeists. Med Sci Sports Exerc1994;26(8):1036-1040.

5. Bonte HA, van den Hoven RJ, van der Sluijs Veer G, Vermes I. The Use of Free Cortisol Index for Laboratory Assessment of pituitary-adrenal function. Clin ChemLab Med. 1999;37(2): 127-132. DOI:10.1515/ CCLM.1999.023.

6. Borg G. Perceived exertion as an indicator of somatic stress. Scand J Rehabil Med. 1970;2(2): 92-98.

7. Borg G, Hassmen P, Lagerstrom M. Perceived exertion related to heart rate and blood lactate during arm and leg exercise. Eur J Appl Physiol Occup Physiol. 1987;56(6):679-685.

8. Brien TG. Free cortisol in human plasma. Horm Metab Res. 1980;12(12): 643-650. DOI:10.1055/s-2007-999224.

9. Brien TG. Human corticisteroid binding globulin. Clin Endocrinol1981;14(2): 193-212. DOI: 10.1111/j.1365-2265.1981. tb00616.x.

10. Brien TG. Pathophysiology of free cortisol in plasma. Ann N Y Acad Sci. 1988;538: 130-136.

11. Brien TG, Clerico A, Del Chicca MG, Zucchelli GC. The apparent free cortisol concentration and the Free Cortisol Index: A comparative study. J Nucl Med Allied Sci. 1981;25(1-2):49-51.

12. Coolens J-L, Van Baelen H, Heyns W. Clinical use of unbound plasma cortisol as calculated from total cortisol and corticosteroid-binding globulin. J Steroid Biochem. 1987;26(2):197-202.

13. Cramer SR, Nieman DC, Lee JW. The Effects of Moderate Exercise Training on Psychological well-being and mood state in women. J Psychosom Res. 1991;35(4-5):437-449.

14. Crook D. Multicenter study of endocrine function and plasma lipids and lipoproteins in womenusing oral contraceptives containing desogestrel progestin. UK Desogen Study Group.Contraception. 1997; 55(4):219-224.

15. Dunn JF, Nisula BC, Rodbard D. Transport of steroid hormones: binding of 21 endogenous steroids to both testosterone binding globulin and corticosteroid-binding globulin in human plasma. J Clin Endocrinol Metab. 1981;53(1): 58-68. DOI:10.1210/jcem-53-1-58. 
16. Faude 0 , Meyer T, Urhausen A, Kindermann W. Recovery training in cyclists: ergometric, hormonal and psychometric findings. Scand J Med Sci Sports. 2009;19(3):433-41. doi: 10.1111/j.16000838.2008.00795.x.

17. Fernandez-Real JM, Pugeat M, López-Bermejo A, Bornet H, Ricart W. Corticosteroid-binding globulin affects the relationship between circulating adiponectin and cortisol in men and women. Metabolism. 2005;54(5):584-589. DOI:10.1016/j.metabol.2004.11.015.

18. Fry RW, Morton AR, Garcia-Webb P, Crawford GP, Keast D. Biological responses to overload training in endurance sports. Eur J Appl Physiol. 1992;64: 335-344.

19. Fry RW, Morton AR, Keast D. Overtraining in athletes. An update. Sports Med. 1991;12(1):32-65.

20.Gilenstam KM, Thorsen K, Henriksson-Larsén KB. Physiological correlates of skating performance in women's and men's ice hockey. J Strength Cond Res. 2011;25:2133-2142. doi: 10.1519/ JSC.0b013e3181ecd072.

21. Greydanus DE, Patel DR. The female athlete. Before and beyond puberty. Pediatr Clin North Am. 2002;49(3): 553-580.

22. Halson SL, Jeukendrup AE. Does overtraining exist? An analysis of overreaching and overtraining research. Sports Med. 2004;34(14): 967-981.

23. Hammond GL, Smith CL, Goping IS, Underhill DA, Harley MJ, Reventos J, ea tl. Primary structure of human corticosteroid binding globulin, deduced from hepatic and pulmonary cDNAs, exhibits homology with serine protease inhibitors. Biochemistry. Proc Natl Acad Sci, USA. 1987;84: 5153-5157.

24. Hansen S, Kvorning T, Kjaer M, Sjogaard G.The effect of short-term strength training on human skeletal muscle: the importance of physiologically elevated hormone levels. Scand J Med Sci Sports. 2001;11(6):347-354.

25. Hedelin R, Kentta G, Wiklund U, Bjerle P, Henriksson-Larsen K.Shortterm overtraining: effects on performance, circulatory responses, and heart rate variability. Med Sci Sports Exerc. 2000;32(8):1480-1484.

26. Keenan DM, Roelfsema F, Veldhuis JD. Endogenous ACTH concentration-dependent drive of pulsatile cortisol secretion in the human. Am J Physiol Endocrinol Metab. 2004;287(4): 652-661. DOI:10.1152/ajpendo.00167.2004.

27. Kellmann M. Preventing overtraining in athletes in high-intensity sports and stress/recovery monitoring. Scand J Med Sci Sports. 2010;20 Suppl 2:95-102. doi: 10.1111/j.1600-0838.2010.01192.x.

28. Kentta G, Hassmen P. Overtraining and recovery. A conceptual model. Sports Med. 1998;26(1): 1-16.

29. Kenttä G, Hassmén P, Raglin JS. Training practices and overtraining syndrome in Swedish age-group athletes. Int J Sports Med. 2001;22(6): 460-465. DOI:10.1055/s-2001-16250.

30. Kuipers, H. Training and overtraining: an introduction. Med Sci Sports Exerc. 1998;30:1137-1139.

31. Lehmann M, Foster C, Keul J.Overtraining in endurance athletes: a brief review. Med Sci Sports Exerc. 1993;25(7):854-862.

32. Lehmann M, Gastmann U, Petersen KG, Bachl N, Seidel A, Khalaf AN Keul J.Training-overtraining: performance, and hormone levels, after a defined increase in training volume versus intensity in experienced middle- and long-distance runners. Br J Sports Med. 1992;26(4): 233242.

33. Lehmann MJ, Lormes W, Opitz-Gress A, Steinacker JM, Netzer N, Foster $\mathrm{C}$, ea tl.Training and overtraining: an overview and experimental results in endurance sports. J Sports Med Phys Fitness. 1997;37(1):717.

34. Lewis JG, Bagley CJ, Elder PA, Bachmann AW, Torpy DJ. Plasma free cortisol fraction reflects levels of functioning corticosteroid-binding globulin. Clin Chim Acta. 2005;359(1-2):189-194.

35. McNair DM, Lorr M, Dropplemann DM. Profile of Mood States Manual. San Diego: Educational and Industrial Testing Service. (E. and I. T. Service, Ed.). San Diego. 1971.

36. Mendel CM. The free hormone hypothesis: A physiologically based mathematical model. Endocr Rev. 1989; 10(3):232-274.

37. Nathorst-Böös J, Stock S, von Schultz B. Effects of oophorectomy and estrogen treatment on basal levels and 24-h profiles of oxytocin. Gynecol Endocrinol. 1994;8(2):127-132.

38. Nilsson-Ehle P, Berggren Söderlund M, Theodorsson E (ed). Klinsik kemi i praktisk medicin.(8:e ed.).Lund: Studentlitteratur, 2012.

39. Nolten WE, Rueckert PA, Lindheimer MD, Oparil S, Ehrlich EN. A simple method for determining the free cortisol index in plasma: measurements in human pregnancy. J Lab Clin Med. 1979;93(1): 146-153.

40. Raglin JS, Morgan WP, O'Connor PJ. Changes in mood states during training in female and male college swimmers. Int J Sports Med. 1991;12(6):585-589. DOI:10.1055/s-2007-1024739.

41. Rechichi C, Dawson B, Goodman C. Athletic performance and the oral contraceptive. Int J Sports Physiol Perform. 2009;4(2): 151-62.

42. Rosner $\mathrm{W}$. The functions of corticosteroid-binding globulin and sex hormone-binding globulin: Recent Advances. Endocr Rev. 1990;11(1):80-91. DOI:10.1210/edrv-11-1-80.

43. Roth-Isigkeit AK, Dibbelt L, Schmucker P. Blood levels of corticosteroid-binding globulin, total cortisol and unbound cortisol i patients undergoing coronary artery bypass grafting surgery with cardiopulmonary bypass. Steroids. 2000;65(9):513-520.

44. Urhausen A, Gabriel H, Kindermann W. Blood hormones as markers of training stress and overtraining. Sports Med. 1995;20(4):251-276.

45. Urhausen A, Kindermann W. Diagnosis of overtraining: what tools do we have? Sports Med2002;32(2): 95-102.

46. Uusitalo ALT, Huttunen P, Hanin Y, Uusitalo AJ, Rusko HK. Hormonal responses to endurance training and overtraining in female athletes. Clin J Sport Med. 1998;8(3): 178-186.

47.Vervoorn C, Vermulst, LJ, Boelens-Quist AM, Koppeschaar HPF, Erich WBM, Thijssen JHH, ea tl. Seasonal changes in performance and free testosterone: cortisol ratio in female rowers. Eur J Appl Physiol. 1992;64(1):14-21.

48. Wiegratz I, Jung-Hoffman H, Kuhl H. Effect of two oral contraceptives containing ethinylestradiol and gestodene or norgestimate upon androgen parameters and serum binding proteins. 1995; 51:341-346.

49. Wiegratz I, Kutschera E, Lee JH, Moore C, Mellinger U, Winkler UH, ea tl. Effect of four different oral contraceptives on various sex hormones and serum-binding globulins. Contraception. 2003;67(1):25-32. 